Egyptian

Orthodontic Journal

\title{
EFFECT OF SALIVA CONTAMINATION ON THE SHEAR BOND STRENGTH OF THE CONVENTIONAL ADHESIVE AND THE SELF-ETCH PRIMER/ADHESIVE
}

\author{
Hatem Saif El Din, BDS, MSc*, \\ Noha E. Sabet, BDS, MSc, PhD*, \\ Khaled M. Fawzy, BDS, MSc, PhD ${ }^{\star \star \star}$
}

ABSTRACT

Objective: The aim of this study was to evaluate the effect of saliva contamination on the shear bond strength of the conventional adhesive and the self-etch primer/adhesive. Material and Methods: Eighty human maxillary premolars were used in this study. They were randomly divided into 2 equal groups. In group I $(\mathcal{N}=40)$, Monolok2 conventional adhesive was used to bond brackets to the enamel surface. In group II $(\mathcal{N}=40)$, Brajen Unibond self-etch primer/adhesive was used to bond brackets to the enamel surface without acid etching. Each group was further subdivided into 4 equal subgroups according to enamel surface condition. Premolar brackets were bonded to the teeth according to the manufacturer instructions. Each specimen was mounted in an Instron Universal Testing Machine and tested to failure in shear mode. Results: Results revealed highly significant differences between subgroups in group I and group II. Conclusion: Conventional bonding system is less reliable in different saliva contamination

* Assistant lecturer, Orthodontic Department, Faculty of Dentistry, Ain Shams University, Cairo, Egypt.

**Associate Professor, Orthodontic Department, Faculty of Dentistry, Ain Shams University, Cairo, Egypt.

**** Professor and Chairman, Orthodontic Department, Faculty of Dentistry, Ain Shams University, Cairo, Egypt.

Corresponding Author: Hatem Saif El Din, Orthodontic Department, Faculty of Dentistry, Ain Shams University, Cairo, Egypt. (e-mail: hatemsaifeldin@gmail.com) 
Egyptian

Orthodontic Journal

\section{conditions. The behavior of the material was less predictable than the self-etch primer/adhesive system.}

\section{INTRODUCTION}

The direct bonding technique involves conditioning of the enamel surface with phosphoric acid ${ }^{1}$. Acid-etching technique has many undesirable disadvantages ${ }^{2,3}$. This technique necessitates strict adherence to a dry field ${ }^{2}$ as success of resin bonding systems is negatively affected by contamination with oral fluids such as saliva and plasma ${ }^{4}$. Salivary contamination of etched enamel for 1 second or longer results in the formation of surface coating that could not be removed by water wash. It would be necessary to repeat the etching procedure to ensure adequate bonding to resin material if salivary contamination of an etched enamel surface occur 5 .

Searching for improved physical characteristics has lead to the development of self-etch primer/adhesive ${ }^{6}$. This system proposed many advantages such as elimination of multi-step acid etching, reducing residual adhesive at debonding, and decreasing the depth of enamel dissolution ${ }^{3}$. This system has the potential to be successfully used in bonding orthodontic brackets even after light salivary contamination due to their hydrophilic nature ${ }^{7,8}$. Therefore, it would be an advantage to find a material that would further improve the bonding procedure while maintaining a clinically acceptable bond strength ${ }^{9}$.

Previous studies comparing the conventional bonding systems and the selfetch primer/adhesive systems under different enamel surface conditions have showed conflicting results ${ }^{10-20}$.

In light of these data, there has been a need to conduct a comparison between the conventional acid etching bonding system and the self-etch primer bonding system in terms of their shear bond strength employing both dry and contaminated conditions.

\section{Material and Methods}

\section{Teeth:}

Eighty recently extracted human maxillary premolars were collected for the study. The teeth were washed with a toothbrush for 20 seconds. Then they were stored in saline solution between 1 and 6 months until the time of testing ${ }^{16,21}$. Saline was changed weekly to avoid deterioration ${ }^{22}$.

Volume 32 - December 2007 
The criteria for tooth selection included: sound teeth with intact buccal enamel and no pretreatment with any chemical agents.

Enamel surface was cleansed for 10 seconds with a non-fluorinated pumice paste using rubber prophylactic cup in a low-speed handpiece. A circular motion was used to avoid damage to any area of the enamel surface. Then each tooth was thoroughly rinsed with water for 20 seconds then completely dried.

\section{Brackets:}

Premolar stainless steel edgewise 0.022 inch slot brackets (American Orthodontics, Sheboygan, USA) were used. The average surface area of the bracket base was $11.2 \mathrm{~mm}^{2}$.

Bonding procedure The teeth were randomly divided into 2 equal groups:

Group I (N=40): Monolok $^{2}$ (Rocky Mountain Orthodontics, Denver, Colorado, USA) conventional adhesive was used according to the manufacturer instructions. This group was divided into 4 subgroups:

In subgroup IA $(\mathbf{n = 1 0})$, Monolok ${ }^{2}$ was used to bond brackets to dry enamel surface. The teeth were etched using 35\% phosphoric acid for 15 seconds, then rinsed for 20 seconds and dried with oil-free air stream for 10 seconds. A thin coat of sealant resin was applied using a disposable brush. A uniform thin layer of adhesive was applied to the bracket base using an applicator. A force gauge (Dentaurum, Turnstrabe, Ispringen, USA) was used to apply a standardized pressure force of 300 grams to seat each bracket in place $^{8,9,15,19,23-25}$. After the bracket was bonded, excess adhesive was removed with sharp scaler. Light curing was done for 20 seconds from the mesial side and 20 from the distal side. Blue Phase C8 LED light curing unit (Ivoclar Vivadent, USA) was used.

In subgroup IB $(\mathbf{n}=\mathbf{1 0})$, the same procedure as subgroup IA was done but with contamination of the tooth surface with a coat of Oralube artificial saliva (Orion Laboratories, Balcatta, Australia) before priming. The artificial saliva was applied with a dropper to the labial surface.

In subgroup IC $(\mathbf{n = 1 0})$, the same procedure as subgroup IA was done but with contamination of the tooth surface with saliva after priming.

In subgroup ID $(\mathbf{n = 1 0})$, the same procedure as subgroup IA was done but with contamination of the tooth surface with saliva before and after priming.

Group II (N=40): Brajen Unibond (Ortho-Byte, Wilmington, USA) selfetch primer/adhesive was used according to the manufacturer instructions. This group was divided into 4 subgroups: 
In subgroup IIA $(\mathbf{n}=\mathbf{1 0})$, Brajen Unibond was used to bond brackets to the dry enamel surface. It is supplied as two primer bottles (primer A) and (Primer B). The mixture of Primer A and Primer B was applied to enamel surface for 5 seconds with a disposable applicator tip which was left on the tooth surface for 20 seconds before application of the adhesive. A uniform thin layer of adhesive was applied to the bracket base using an applicator and then the bracket was bonded. The same procedure for bracket placement and curing was followed as subgroup IA.

In subgroup IIB $(\mathbf{n}=\mathbf{1 0})$, the same procedure as subgroup IIA was done but with contamination of the tooth surface with saliva before priming.

In subgroup IIC $(\mathbf{n = 1 0})$, the same procedure as subgroup IIA was done but with contamination of the tooth surface with saliva after priming.

In subgroup IID $(\mathbf{n}=\mathbf{1 0})$, the same procedure as subgroup IIA was done but with contamination of the tooth surface with saliva before and after priming.

\section{Debonding procedure:}

Teeth were embedded in self-cure acrylic resin blocks $(1.5 \mathrm{~mm} \times 2.5 \mathrm{~mm})$ using custom made form made of Teflon. Each tooth facial surface was aligned perpendicular with the base of the mold, i.e., each tooth was oriented so that its labial surface would be parallel to the shearing force using a mounting jig. Teeth were then stored in distilled water at $37^{\circ} \mathrm{C}$ for 24 hours until the time of debonding ${ }^{10,26-33}$. Each specimen was mounted in an Instron Universal Testing Machine (Commten industries, Florida, USA) and tested to failure in shear mode using a stainless steel blade applied perpendicular to the resin-enamel-bracket interface in an occlusogingival direction at a crosshead speed of 0.5 $\mathrm{mm} / \mathrm{min}^{17,23,33-37}$. The maximum load necessary to debond or initiate bracket fracture was recorded in Newton and then converted into MegaPascal units as a ratio of Newton to surface area of the bracket.

\section{Statistical Analysis:}

1. Descriptive statistics including the mean and standard deviation values.

2. ANOVA was used as a test of significance between the samples means of group I subgroups. When significant differences were present, Post hoc test (Tukey HSD) was used to determine which means were significantly different from each other. The same was done for group II subgroups. 
3. Student's t-test comparisons were preformed between matching subgroups in the group I and group II.

4. The Weibull regression equation was used.

\section{RESULTS}

The descriptive statistics on the shear bond strength (in megapascals) for group I and group II are presented in (table 1) and (table 2) respectively.

The results of the ANOVA indicated the presence of highly significant differences between the subgroups of group I $(\mathrm{P}<0.0001)$. Tukey test showed that the shear bond strength was significantly higher in subgroup IA (no contamination by saliva) than that of the other subgroups IB, IC and ID where saliva contamination occurred. Also, there was no significant difference in the shear bond strength between subgroups IB (contamination by saliva before priming) and ID (contamination by saliva before and after priming).

In group II, the results of the ANOVA showed highly significant differences between the subgroups $(\mathrm{P}<0.0001)$. The shear bond strength was significantly higher in the subgroup IIA (no contamination by saliva) than the other subgroups where saliva contamination occurred which showed no significant differences between them.

The Student's t-test comparisons were preformed between similar subgroups in group I and group II.

Subgroup IA showed a significantly higher shear bond strength than subgroup IIA $(\mathrm{P}=0.03)(\mathrm{t}=2.38)$. Subgroup IIB had highly significantly shear bond strength than subgroup IB $(\mathrm{P}<0.0001)(\mathrm{t}=-18.41)$. Although subgroup IIC showed higher shear bond strength than subgroup IC, this difference was statistically non significant $(\mathrm{P}=0.3) \quad(\mathrm{t}=1.13)$. Subgroup IID had highly significantly shear bond strength than subgroup ID $(\mathrm{P}<0.0001)(\mathrm{t}=-9.10)$.

Bond strength data was analyzed in more detail using Weibull analysis as shown in (table 3) for group I and (table 4) for group II. Values of probability of failure at any predetermined level of stress for group I and group II are given in (Fig. 1) and (Fig. 2) respectively.

There was a wide scatter of the Weibull modulus (m) for group I subgroups. The low values of $(\mathrm{m})$ in subgroup IB and subgroup ID indicate that the material behavior is of low predictability. In group II subgroups, all the 
values are showing that the self-etch primer/adhesive is a more predictable material at different enamel surface treatments.

At a stress of $8 \mathrm{Mpa}$, the probability of bond survival in group I varied from $99.2 \%$ for subgroup IA to $0 \%$ for subgroup IB and subgroup ID. In group II subgroups, the probability of bond survival variation was from $98.6 \%$ for subgroup IIA to $52.9 \%$ for subgroup IID.

For group I, the graph shows a wide variation of survival probability at any shear load with subgroup IB and subgroup ID lines shifted to the left indicating very low survival probabilities even at low shear load stresses. As for group II, there is a narrow variation of survival probability and the whole graph is shifted to the right at any given value of applied force indicating a higher material performance.

\section{DISCUSSION}

The present study evaluated the use of a self-etch primer as compared with the conventional bonding procedure. This study showed that non contaminated enamel surfaces had the highest bond strength for both conventional and selfetch primer systems. This is in agreement with some previous studies that evaluated the shear bond strength of conventional ${ }^{38}$ and self-etch primers ${ }^{28}$.

Previous studies comparing the conventional system and the self-etch primer/adhesive systems under dry conditions have showed conflicting results. Arnold et $\mathrm{al}^{10}$ and others ${ }^{11-13}$ reported no significant differences between the two systems but Bishara et al ${ }^{14,15,24}$ and others ${ }^{9,16-20}$ found that the bond strength achieved with the self-etch primer was significantly lower than that achieved with conventional system. This was confirmed in the present study.

Enamel contamination with saliva can occur at two critical times of the bonding procedure: after the tooth has been etched and after the primer has been applied. Bonding can be compromised at both times.

Under saliva contamination conditions, both conventional and self-etch primer produced significantly lower bond strength values compared with those achieved under dry conditions. The self-etch primer produced higher bond strength values compared with those attained by conventional system under saliva contamination conditions. Moreover, the self-etch primer showed no significant difference in the shear bond strength under the three different saliva contamination situations. 
Table (1): Descriptive statistics and the results of ANOVA and Tukey test comparing the shear bond strength (in MPa) of Conventional Primer/Adhesive (Group I).

\begin{tabular}{|l|c|c|c|c|c|}
\hline $\begin{array}{c}\text { Conventional Primer/Adhesive } \\
\text { (Group I) }\end{array}$ & No. & Mean & $\begin{array}{c}\text { Standard } \\
\text { deviation (SD) }\end{array}$ & Range & $\begin{array}{c}\text { Tukey } \\
\text { test* }\end{array}$ \\
\hline Subgroup IA (Dry) & 10 & 19.77 & 3.95 & $14.07-23.95$ & $\mathrm{~A}$ \\
\hline $\begin{array}{l}\text { Subgroup IB (Contamination } \\
\text { before priming) }\end{array}$ & 10 & 0.86 & 0.33 & $0.47-1.59$ & $\mathrm{~B}$ \\
\hline $\begin{array}{l}\text { Subgroup IC (Contamination } \\
\text { after priming) }\end{array}$ & 10 & 9.45 & 1.54 & $7.94-13.09$ & $\mathrm{C}$ \\
\hline $\begin{array}{l}\text { Subgroup ID (Contamination } \\
\text { before and after priming) }\end{array}$ & 10 & 0.72 & 0.35 & $0.19-1.42$ & $\mathrm{~B}$ \\
\hline F=178.56 P<0.0001 & & & & \\
\hline
\end{tabular}

*Groups with different letters are significantly different from each other.

Table (2): Descriptive statistics and the results of ANOVA and Tukey test comparing the shear bond strength (in MPa) of self-etch Primer/Adhesive (Group II).

\begin{tabular}{|l|c|c|c|c|c|}
\hline \multicolumn{1}{|c|}{$\begin{array}{c}\text { Self-etch Primer/Adhesive } \\
\text { (Group II) }\end{array}$} & No. & Mean & $\begin{array}{c}\text { Standard } \\
\text { deviation (SD) }\end{array}$ & Range & $\begin{array}{c}\text { Tukey } \\
\text { test* }\end{array}$ \\
\hline Subgroup IIA (Dry) & 10 & 16.09 & 2.90 & $10.50-19.73$ & $\mathrm{D}$ \\
\hline $\begin{array}{l}\text { Subgroup IIB (Contamination } \\
\text { before priming) }\end{array}$ & 10 & 10.71 & 1.66 & $7.99-13.67$ & $\mathrm{E}$ \\
\hline $\begin{array}{l}\text { Subgroup IIC (Contamination } \\
\text { after priming) }\end{array}$ & 10 & 10.25 & 1.64 & $8.71-14.10$ & $\mathrm{C}$ \\
\hline $\begin{array}{l}\text { Subgroup IID (Contamination } \\
\text { before and after priming) }\end{array}$ & 10 & 8.28 & 2.60 & $4.33-11.61$ & $\mathrm{E}$ \\
\hline F=23.43 P<0.0001 & & & & \\
\hline
\end{tabular}

*Groups with different letters are significantly different from each other. 
Egyptian

Orthodontic Journal

Table (3): Weibull modulus and characteristic strength of Conventional Primer/Adhesive (Group I).

\begin{tabular}{|l|c|c|c|c|c|}
\hline $\begin{array}{c}\text { Conventional Primer/Adhesive } \\
\text { (Group I) }\end{array}$ & $\begin{array}{c}\text { Weibull } \\
\text { modulus } \\
(\mathbf{m})\end{array}$ & $\begin{array}{c}\text { Characteristic } \\
\text { strength } \\
\left(\mathbf{S}_{\mathbf{0}}\right)\end{array}$ & $\begin{array}{c}\text { Shear bond strength } \\
\text { (MPa) at 10\% } \\
\text { probability of failure }\end{array}$ & $\begin{array}{c}\text { Shear bond strength } \\
\text { (MPa) at 90\% } \\
\text { probability of failure }\end{array}$ & $\begin{array}{c}\text { Probability } \\
\text { of failure at } \\
\mathbf{8 ~ M P a}\end{array}$ \\
\hline Subgroup IA (Dry) & 4.9 & 21.6 & 13.6 & 25.6 & $0.8 \%$ \\
\hline $\begin{array}{l}\text { Subgroup IB (Contamination } \\
\text { before priming) }\end{array}$ & 2.9 & 1 & 0.5 & 1.3 & $100 \%$ \\
\hline $\begin{array}{l}\text { Subgroup IC(Contamination } \\
\text { after priming) }\end{array}$ & 6.5 & 10.1 & 7.1 & 11.5 & $19.8 \%$ \\
\hline $\begin{array}{l}\text { Subgroup ID(Contamination } \\
\text { before and after priming) }\end{array}$ & 1.9 & 0.8 & 0.2 & 1.2 & $100 \%$ \\
\hline
\end{tabular}

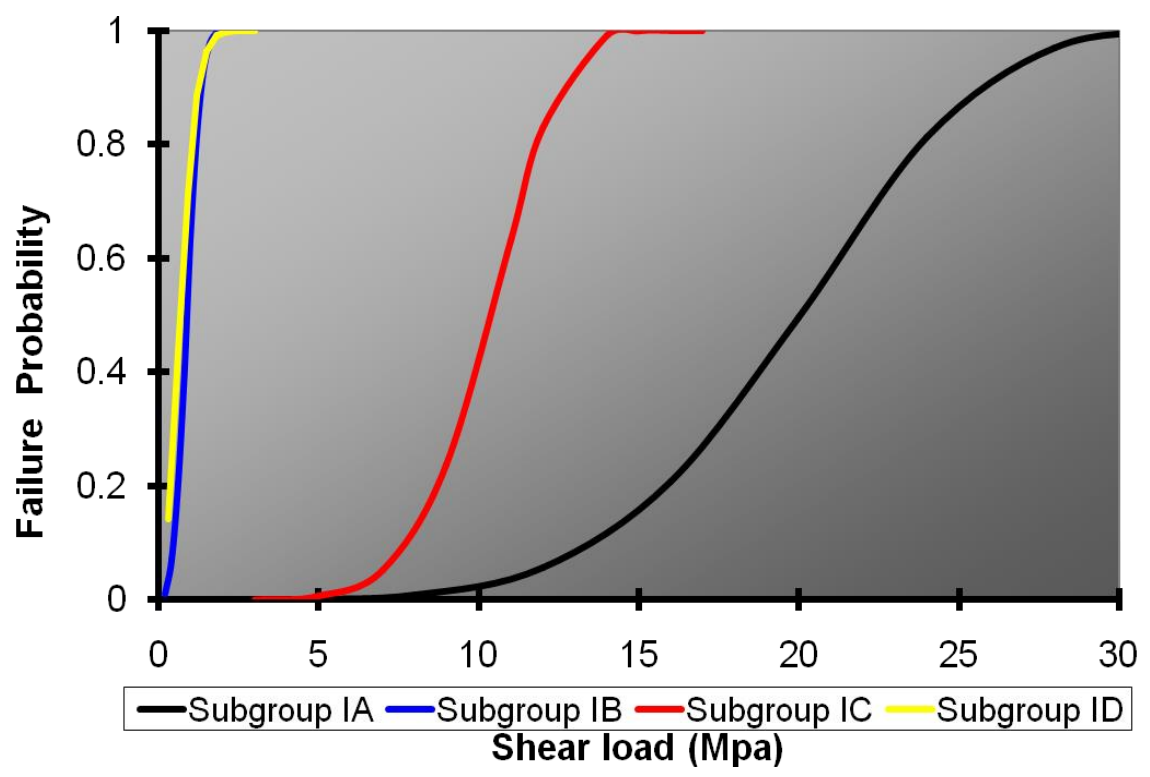

Figure (1): Failure probability versus shear load for conventional primer/adhesive (Group I). 
Egyptian

Orthodontic Journal

Table (4): Weibull modulus and characteristic strength of self-etch Primer/Adhesive (Group II).

\begin{tabular}{|l|c|c|c|c|c|}
\hline \multicolumn{1}{|c|}{$\begin{array}{c}\text { Self-etch Primer/Adhesive } \\
\text { (Group II) }\end{array}$} & $\begin{array}{c}\text { Weibull } \\
\text { modulus } \\
(\mathbf{m})\end{array}$ & $\begin{array}{c}\text { Characteristic } \\
\text { strength } \\
\text { (So) }\end{array}$ & $\begin{array}{c}\text { Shear bond strength } \\
\text { (MPa) at 10\% } \\
\text { probability of failure }\end{array}$ & $\begin{array}{c}\text { Shear bond strength } \\
\text { (MPa) at } \\
\text { 90\% probability of failure }\end{array}$ & $\begin{array}{c}\text { Probabilit } \\
\text { y of failure } \\
\text { at 8 MPa }\end{array}$ \\
\hline Subgroup IIA (Dry) & 5.5 & 17.4 & 11.5 & 20.3 & $1.4 \%$ \\
\hline $\begin{array}{l}\text { Subgroup IIB (Contamination } \\
\text { before priming) }\end{array}$ & 7 & 11.4 & 8.3 & 12.8 & $7.9 \%$ \\
\hline $\begin{array}{l}\text { Subgroup IIC (Contamination } \\
\text { after priming) }\end{array}$ & 6.5 & 11.1 & 7.8 & 12.5 & $11.9 \%$ \\
\hline $\begin{array}{l}\text { Subgroup III (Contamination } \\
\text { before and after priming) }\end{array}$ & 3 & 9.3 & 4.4 & 12.3 & $47.1 \%$ \\
\hline
\end{tabular}

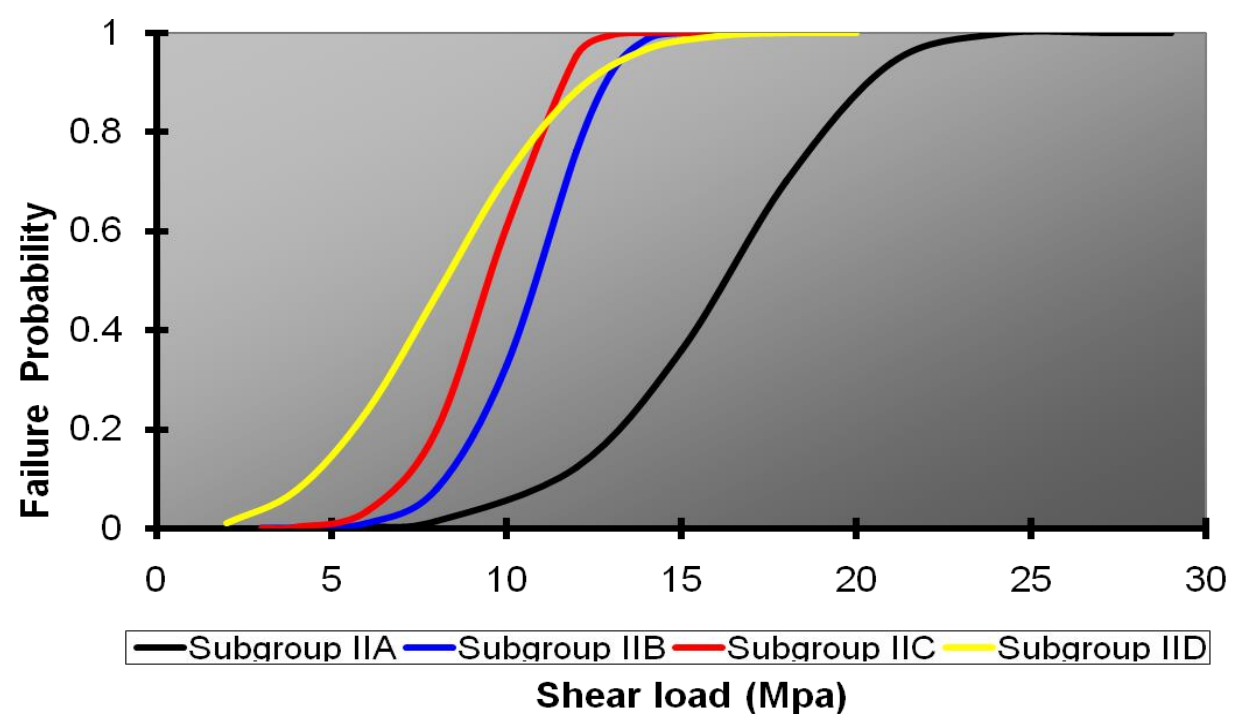

Figure (2): Failure probability versus shear load for self-etch primer/adhesive (Group II). 
When saliva contamination occurred before priming, the conventional system showed significantly lower bond strength than that occurring on dry enamel. These findings confirm that of Grandhi et $\mathrm{al}^{29}$ and Rajagopal et $\mathrm{al}^{39}$ but disagrees with that of Cacciafesta et $\mathrm{al}^{40}$ who found no significant difference at the same enamel surface condition. The self-etch primer also showed significantly lower bond strength than that occurring on dry enamel agreeing with that of Larmour et $\mathrm{al}^{28}$ and Campoy et $\mathrm{al}^{26}$ and while disagreeing with that of Cacciafesta et $\mathrm{al}^{40}$ who found no significant difference in the bond strength at the same enamel surface condition. However, the self-etch primer showed significantly higher bond strength than that of the conventional system. These findings confirm those reported by Cacciafesta et $\mathrm{al}^{40}$.

When saliva contamination occurred after priming, the conventional system showed significantly lower bond strength than that occurring on dry enamel. These finding confirms that of Cacciafesta et $\mathrm{al}^{40}$ while disagreeing with that of Campoy et $\mathrm{al}^{26}$ who showed no significant difference. However, the shear bond strength reading was significantly higher than when saliva contamination occurred before priming. This may be due to the hydrophobic nature of the conventional resin that possibly prevents the saliva from diluting or penetrating the etched enamel surface as suggested by Webster et $\mathrm{al}^{37}$.

The self-etch primer also showed significantly lower bond strength than that occurring on dry enamel when saliva contamination occurred after priming agreeing with that of Cacciafesta et $\mathrm{al}^{40}$ and disagreeing with that of Campoy et $\mathrm{al}^{26}$, Bishara et $\mathrm{al}^{8}$ and Zeppieri et $\mathrm{al}^{41}$ who found no significant difference. The self-etch primer showed no significant difference in the shear bond strength between the saliva contamination before priming and saliva contamination after priming. This agrees with the findings of Zeppieri et $\mathrm{al}^{41}$. Also, the self-etch primer showed higher shear bond strength than that of the conventional system when saliva contamination occurred after priming, yet it was a non significant difference. This finding contradicts that reported by Cacciafesta et $\mathrm{al}^{40}$.

When saliva contamination occurred before and after priming, the conventional system showed significantly lower bond strength than that occurring on dry enamel and that occurring when saliva contamination was present after priming. These findings confirms that of Cacciafesta et $\mathrm{al}^{40}$. However, the conventional system showed non significant difference in shear bond strength values when comparing saliva contamination occurring before and after priming with saliva contamination occurring before priming. 
The self-etch primer showed significantly lower bond strength than that occurring on dry enamel when saliva contamination occurred before and after priming yet non significant difference when compared with the other saliva contamination conditions. This agrees with that of Cacciafesta et $\mathrm{al}^{40}$ and Campoy et $\mathrm{al}^{26}$ and disagreeing with that of Bishara et $\mathrm{al}^{8}$ and Zeppieri et $\mathrm{al}^{41}$ who found no significant difference under the same condition. However, the self-etch primer showed bond strength significantly higher than that of conventional system. These findings confirm those reported by Cacciafesta et $\mathrm{al}^{40}$.

Therefore, the most critical time in saliva contamination for the conventional system is when saliva contamination occurred before priming and when saliva contamination occurred before and after priming. On the contrary, the timing of saliva contamination is not critical for the self-etch primer as all the saliva contamination groups did not show any significant difference between them.

Weibull analysis has been recommended for the study of bond strength ${ }^{42,43}$ as it can predict values within and outside the data set. It has been suggested as an appropriate test for orthodontic bond material testing ${ }^{42}$. This ability to predict the number of bonds likely to fail at a particular bond strength puts laboratory bond strength studies into a clinical scenario ${ }^{30}$.

The scattered values of the Weibull modulus (m) for the conventional adhesive system showed that the material has a wide range of clinical predictability. It shows dramatic difference in its performance according to the enamel surface treatment. The low values of $(\mathrm{m})$ when saliva contamination occurs before priming and when saliva contamination occurs before and after priming suggest that they are the least reliable situations for the conventional adhesive where the material behavior is less predictable.

On the other hand, all the values of Weibull modulus for the self-etch primer are within acceptable range showing that the self-etch primer/adhesive is a more predictable material at different enamel surface treatments. The self-etch primer at any given predetermined level of stress showed high survival probability suggesting a highly reliable performance in a clinical scenario.

Reynolds $^{44}$ suggested that a minimum bond strength of 6-8 MPa was adequate for most clinical orthodontic needs, because these values are considered to be able to withstand masticatory and orthodontic forces. It has been suggested that bond failure rates below $10 \%$ are generally considered to be clinically acceptable ${ }^{45}$. 
Under dry conditions, at the level of stress ( $8 \mathrm{MPa})$, both adhesives' bond failures are within limits reported (below 10\%).

Under all saliva contamination conditions, the conventional system failed to provide values within the acceptable range. The self-etch primer/adhesive system provided adequate bond strength for orthodontic procedures when saliva contamination occurred before priming. When saliva contamination occurred after priming or occurred before and after priming, the self-etch primer bond failures were considered unacceptable when compared with that of clinically acceptable range (below 10\%), yet, they were much higher than that of the conventional system in the same situations. Nevertheless, self-etch primer failure rates results were higher than those reported in a previous study ${ }^{28}$.

\section{CONCLUSIONS}

1. Non-contaminated enamel surfaces had the highest bond strength values for the conventional system and the self-etch primer/adhesive system.

2. Under dry conditions, the self-etch primer/adhesive system produced significantly lower but clinically acceptable bond strength values than that of the conventional system.

3. In all saliva-contaminated conditions, the self-etch primer/adhesive system had higher bond strength values than the conventional system.

4. The behavior the conventional bonding system was less predictable than the self-etch primer/adhesive system in different saliva contamination conditions.

5. Based on these results, the newly introduced self-etch primer/adhesive system can be successfully used for bonding orthodontic brackets under both dry and saliva contaminated enamel surface conditions.

\section{REFERENCES}

1. Bishara S, Olsen M, Damon P, Jakobson J. Evaluation of a new light-cured orthodontic bonding adhesive. Am J Orthod Dentofacial Orthop 1998;114:80-87.

2. Summers A, Kao E, Gilmore J, Gunel E, Ngan P. Comparison of bond strength between a conventional resin adhesive and a resin-modified glass ionomer adhesive: An in vitro and in vivo study. Am J Orthod Dentofacial Orthop 2004;126:200-206. 
3. Bishara SE, Oonsombat C, Ajlouni R, Denehy G. The effect of saliva contamination on shear bond strength of orthodontic brackets when using a self-etch primer. Angle Orthod 2002;72:554-557.

4. Diedrich P. Enamel alterations from bracket bonding and debonding: A study with the scanning electron microscope. Am J Orthod Dentofacial Orthop 1981;71:500-522.

5. Silverstone L, Hicks M, Featherstone M. Oral fluid contamination of etched enamel surfaces: an SEM study. J Am Dent Assoc 1985;110:329-332.

6. Hannig M, Reinhardt K, Bott B. Self-etching primer vs phosphoric acid: an alternative concept for composite-to-enamel bonding. Oper Dent 1999;24:172-180.

7. Bishara S, Gordan V, VonWald L, Olson M. Effect of an acidic primer on shear bond strength of orthodontic brackets. Am J Orthod Dentofacial Orthop 1998;114:243-247.

8. Bishara S, Oonsombat C, Ajlouni R, Denehy G. The effect of saliva contamination on shear bond strength of orthodontic brackets when using a self-etch primer. Angle Orthod 2002;72:554-557.

9. Yamada R, Hayakawa T, Kasai K. Effect of using self-etching primer for bonding orthodontic brackets. Angle Orthod 2002;72:558-564.

10. Arnold R, Combe E, Warford J, Jr. Bonding of stainless steel brackets to enamel with a new self-etching primer. Am J Orthod Dentofacial Orthop 2002;122:274-276.

11. Dorminey J, Dunn W, Taloumis L. Shear bond strength of orthodontic brackets bonded with a modified 1-step etchant-and-primer technique. Am J Orthod Dentofacial Orthop 2003;124:410-413.

12. Saito K, Sirirungrojying S, Meguro D, Hayakawa T, Kasai K. Bonding durability of using self-etching primer with 4-META/ MMA-TBB resin cement to bond orthodontic brackets. Angle Orthod 2005;75:260-265.

13. Kimura T, Dunn W, Taloumis L. Effect of fluoride varnish on the in vitro bond strength of orthodontic brackets using a self-etching primer system. Am J Orthod Dentofacial Orthop 2004;125:351-356.

14. Bishara S, VonWald L, Laffoon J, Warren J. Effect of a self-etch primer/adhesive on the shear bond strength of orthodontic brackets. Am J Orthod Dentofacial Orthop 2001;119:621-624. 
15. Bishara S, Ajlouni R, Laffoon J, Warren J. Effect of a fluoride-releasing selfetch acidic primer on the shear bond strength of orthodontic brackets. Angle Orthod 2002;72:199-202.

16. Grubisa H, Heo G, Raboud D, Glover K, Major P. An evaluation and comparison of orthodontic bracket bond strengths achieved with self-etching primer. Am J Orthod Dentofacial Orthop 2004;126:213-219.

17. Aljubouri Y, Millett D, Gilmour WH. Laboratory evaluation of a self-etching primer for orthodontic bonding. Eur J Orthod 2003;25:411-415.

18. Kawasaki M, Hayakawa T, Takizawa T, Sirirungrojying S, Saitoh K, Kasai K. Assessing the performance of a methyl methacrylate-based resin cement with self-etching primer for bonding orthodontic brackets. Angle Orthod 2003;73:702-709.

19. Cehreli Z, Altay N. Effects of a nonrinse conditioner and $17 \%$ ethylenediaminetetraacetic acid on the etch pattern of intact human permanent enamel. Angle Orthod 2000;70:22-27.

20. Pithon M, Dos Santos R, de Oliveira M, Ruellas A, Romano F. Metallic brackets bonded with resin-reinforced glass ionomer cements under different enamel conditions. Angle Orthod 2006;76:700-704.

21. Eliades T, Katsavrias E, Eliades G. Moisture-insensitive adhesives: reactivity with water and bond strength to wet and saliva-contaminated enamel. Eur J Orthod 2002;24:35-42.

22. von Fraunhofer J, Allen D, Orbell G. Laser etching of enamel for direct bonding. Angle Orthod 1993;63:73-76.

23. Usumez S, Orhan M, Usumez A. Laser etching of enamel for direct bonding with an Er,Cr:YSGG hydrokinetic laser system. Am J Orthod Dentofacial Orthop 2002;122:649-656.

24. Bishara S, Gordan V, VonWald L, Jakobsen J. Shear bond strength of composite, glass ionomer, and acidic primer adhesive systems. Am J Orthod Dentofacial Orthop 1999;115:24-28.

25. Sirirungrojying S, Saito K, Hayakawa T, Kasai K. Efficacy of using selfetching primer with a 4-META/MMA-TBB resin cement in bonding orthodontic brackets to human enamel and effect of saliva contamination on shear bond strength. Angle Orthod 2004;74:251-258. 
26. Campoy M, Vicente A, Bravo L. Effect of saliva contamination on the shear bond strength of orthodontic brackets bonded with a self-etching primer. Angle Orthod 2005;75:865-869.

27. Abu Alhaija E, Al-Wahadni A. Evaluation of shear bond strength with different enamel pre-treatments. Eur J Orthod 2004;26:179-184.

28. Larmour C, Stirrups D. An ex vivo assessment of a bonding technique using a self-etching primer. J Orthod 2003;30:225-228.

29. Grandhi R, Combe E, Speidel T. Shear bond strength of stainless steel orthodontic brackets with a moisture-insensitive primer. Am J Orthod Dentofacial Orthop 2001;119:251-255.

30. Gardner A, Hobson R. Variations in acid-etch patterns with different acids and etch times. Am J Orthod Dentofacial Orthop 2001;120:64-67.

31. Torii Y, Itou K, Nishitani Y, Yoshiyama M, Ishikawa K, Suzuki K. Effect of self-etching primer containing $\mathrm{N}$-acryloyl aspartic acid on enamel adhesion. Dent Mater 2003;19:253-258.

32. Vicente A, Bravo L, Romero M. Self-etching primer and a non-rinse conditioner versus phosphoric acid: alternative methods for bonding brackets. Eur J Orthod 2006;28:173-178.

33. Cal-Neto J, Carvalho F, Almeida R, Miguel J. Evaluation of a new selfetching primer on bracket bond strength in vitro. Angle Orthod 2006;76:466-469.

34. Surmont P, Dermaut L, Martens L, Moors M. Comparison in shear bond strength of orthodontic brackets between five bonding systems related to different etching times: An in vitro study. Am J Orthod Dentofacial Orthop 1992;101:414-419.

35. Wiltshire W. Shear bond strengths of a glass ionomer for direct bonding in orthodontics. Am J Orthod Dentofacial Orthop 1994;106:127-130.

36. Harari D, Gillis I, Redlich M. Shear bond strength of a new dental adhesive used to bond brackets to unetched enamel. Eur J Orthod 2002;24:519-523.

37. Webster M, Nanda R, Duncanson M, Jr., Khajotia S, Sinha P. The effect of saliva on shear bond strengths of hydrophilic bonding systems. Am J Orthod Dentofacial Orthop 2001;119:54-58. 
38. Itoh T, Fukushima T, Inoue Y, Arita S, Miyazaki K. Effect of water, saliva and blood contamination on bonding of metal brackets with a 4-META/MMA/TBB resin to etched enamel. Am J Dent 1999;12:299-304.

39. Rajagopal R, Padmanabhan S, Gnanamani J. A comparison of shear bond strength and debonding characteristics of conventional, moisture-insensitive, and self-etching primers in vitro. Angle Orthod 2004;74:264-268.

40. Cacciafesta V, Sfondrini M, De Angelis M, Scribante A, Klersy C. Effect of water and saliva contamination on shear bond strength of brackets bonded with conventional, hydrophilic, and self-etching primers. Am J Orthod Dentofacial Orthop 2003;123:633-640.

41. Zeppieri I, Chung C, Mante F. Effect of saliva on shear bond strength of an orthodontic adhesive used with moisture-insensitive and self-etching primers. Am J Orthod Dentofacial Orthop 2003;124:414-419.

42. Fox N, McCabe J, Buckley J. A critique of bond strength testing in orthodontics. Br J Orthod 1994;21:33-43.

43. Little wood SJ, Mitchell L, Greenwood DC, Bubb NL, Wood DJ. Investigation of a hydrophilic primer for orthodontic bonding: an in vitro study. Br J Orthod 2000;27:181-186.

44. Reynolds IR. A review of direct orthodontic bonding. Br J Orthod 1975;2:171-178.

45. Mavropoulos A, Karamouzos A, Kolokithas G, Athanasiou AE. In vivo evaluation of two new moisture-resistant orthodontic adhesive systems: a comparative clinical trial. J Orthod 2003;30:139-147. 
